\begin{tabular}{|c|c|c|c|}
\hline \multirow{3}{*}{$\begin{array}{r}\text { Case Reports in } \\
\text { Gastroenterology }\end{array}$} & \multicolumn{2}{|c|}{ Case Rep Gastroenterol 2017;11:95-102 } & \multirow[b]{2}{*}{$\begin{array}{l}\text { Karger } \\
\text { Open access }\end{array}$} \\
\hline & $\begin{array}{l}\text { DOI: } 10.1159 / 000456656 \\
\text { Publisnea onine: TVIrarch 3, } 2017\end{array}$ & $\begin{array}{l}\text { @ } 2017 \text { The Author(s)Published by S. } \\
\text { Karger AG, Basel } \\
\text { www.karger.com/crg }\end{array}$ & \\
\hline & $\begin{array}{l}\text { This article is licensed under } t \\
\text { International License (CC BY-N } \\
\text { Usage and distribution for comm }\end{array}$ & $\begin{array}{l}\text { nons Attribution-NonCommercial } 4.0 \\
\text { ger.com/Services/OpenAccessLicense) } \\
\text { uires written permission. }\end{array}$ & \\
\hline
\end{tabular}

\title{
Gallstone Ileus Caused by Cholecystocolonic Fistula and Gallstone Impaction in the Sigmoid Colon: Review of the Literature and Novel Surgical Treatment with Trephine Loop Colostomy
}

\author{
James W. O'Brien Lucy-Anne Webb Luke Evans Chris Speakman
} Irshad Shaikh

Department of General Surgery, Norfolk and Norwich University Hospital, Norwich, UK

\section{Keywords}

Gallstone · Sigmoid · Ileus · Cholecystoenteric fistula · Trephine loop colostomy · Bowel obstruction

\begin{abstract}
Gallstone ileus is an uncommon cause of intestinal obstruction and occurs following the formation of a cholecystoenteric fistula, permitting passage of gallstones into the gastrointestinal tract. Impaction of a gallstone in the sigmoid colon is rare and is usually at sites of previous colonic disease. Definitive management can be challenging due to the advanced age and co-morbidity usually seen in this group of patients. We describe a patient successfully managed with on-table endoscopy and, under local anaesthetic, the formation of a left iliac fossa trephine loop colostomy, permitting an enterolithotomy to deliver the stone whilst accommodating for severe pre-existing distal sigmoid diverticular disease. A review of the literature identified various endoscopic and surgical treatments that, depending on local expertise and patient characteristics, can be considered on a case-by-case basis. We advocate the management described in this case for patients presenting with large bowel obstruction due to
\end{abstract}




\section{Case Reports in Gastroenterology}

Case Rep Gastroenterol 2017;11:95-102 DOI: $10.1159 / 000456656$

c 2017 The Author(s). Published by S. Karger AG, Basel www.karger.com/crg

O'Brien et al.: Gallstone Ileus Caused by Cholecystocolonic Fistula and Impaction in the Sigmoid Colon: Novel Surgical Treatment with Trephine Loop Colostomy

gallstone ileus, with a background of diverticular disease and who are not fit for general anaesthetic or formal bowel resection, as an alternative to medical palliation alone.

(C) 2017 The Author(s)

Published by S. Karger AG, Basel

\section{Background}

Gallstone ileus occurs following the formation of a cholecystoenteric fistula, most commonly to the duodenum or stomach, but also to the colon. Gallstones can then pass into the gastrointestinal tract causing bowel obstruction. Gallstone ileus is the primary cause in less than $0.1 \%$ cases of mechanical bowel obstruction [1]. A cholecystocolonic fistula commonly occurs at the hepatic flexure after repeated episodes of cholecystitis. Impaction of a gallstone in the sigmoid colon causing large bowel obstruction is rare and is usually at sites of previous inflammation or colonic disease. We describe an elderly co-morbid patient with a cholecystocolonic fistula, presenting with large bowel obstruction due to gallstone impaction in the sigmoid colon. Methods for definitive removal of the impacted stone include laparotomy with simple enterolithotomy or sigmoid resection and end stoma formation, or the use of endoscopic techniques such as balloon dilatation or lithotripsy [2-4]. In patients with a preexisting diseased bowel, concerns exist over the safest intervention [5]. This case was managed successfully through combined surgery and endoscopy; under local anaesthetic a left iliac fossa trephine incision allowed an enterolithotomy in order to extract the stone, which was gently mobilized first with on-table sigmoidoscopy. A loop colostomy was then created due to concerns over bowel quality, serosal tears, and severe diverticular disease at the site of stone impaction. This novel, safe approach allows elderly, co-morbid patients to be treated without general anaesthetic or major surgery, and accommodates for severe pre-existing colonic disease.

\section{Case Report}

An 88-year-old Caucasian female was admitted with a 7-day history of absolute constipation associated with lack of appetite and colicky abdominal pain. The patient had no surgical history and a medical history of diverticular disease, hypertension, severe pulmonary hypertension, and atrial fibrillation, for which she was prescribed warfarin.

On examination body mass index was 25 , and the patient was haemodynamically stable. Her abdomen was distended and diffusely tender. Digital rectal examination revealed an empty rectum. Haematological and biochemical investigation revealed a C-reactive protein of $177 \mathrm{mg} / \mathrm{L}$ (ref. $<10 \mathrm{mg} / \mathrm{L}$ ) and deranged liver function, with alkaline phosphatase 407 IU/L (ref. 30-120 IU/L), aspartate aminotransferase 60 IU/L (ref. 6-40 IU/L), and total bilirubin $35 \mu \mathrm{mol} / \mathrm{L}(<21 \mu \mathrm{mol} / \mathrm{L})$. Computed tomography $(\mathrm{CT})$ of the abdomen and pelvis revealed gallstones in the gallbladder, with a thickened, enhancing gallbladder wall with fistula to the ascending colon (Fig. 1). There was pneumobilia and several non-obstructing stones in the common bile duct, which was dilated to $18 \mathrm{~mm}$, ending at the ampulla in a short enhancing stricture, and also intrahepatic bile duct dilatation. The large bowel was dilated, with a transition point in the mid-sigmoid colon at the level of a $4.4 \times 2.7 \mathrm{~cm}$ gallstone in the colon, with diverticulosis and mural thickening at this point suggestive of a diverticular stricture (Fig. 2). 


\section{Case Reports in Gastroenterology}

Case Rep Gastroenterol 2017;11:95-102

DOI: $10.1159 / 000456656$

(c) 2017 The Author(s). Published by S. Karger AG, Basel www.karger.com/crg

O'Brien et al.: Gallstone Ileus Caused by Cholecystocolonic Fistula and Impaction in the Sigmoid Colon: Novel Surgical Treatment with Trephine Loop Colostomy

The patient was diagnosed with mechanical large bowel obstruction secondary to gallstone impaction in a diverticular stricture of the sigmoid colon, arising from cholecystocolonic fistula formation. Management involved making the patient "nil by mouth", placement of a nasogastric tube, and intravenous fluids. Definitive management was attempted with flexible sigmoidoscopy, where the stone could be visualized and a snare passed through the diverticular stricture, but it was not possible to retrieve the stone beyond a sharply bending recto-sigmoid junction. When combined with the large size of the stone and poor bowel integrity due to diverticulosis of the sigmoid, attempted removal via the distal route was abandoned.

The patient was deemed not fit for general anaesthetic due to her severe pulmonary hypertension. With the patient's consent, the decision was made to repeat the sigmoidoscopy, assisted by a simultaneous trephine loop colostomy under local anaesthetic.

On-table flexible sigmoidoscopy allowed a snare to be applied to the gallstone. Under local anaesthetic a small trephine incision was made in the left iliac fossa. Using the snare, the gallstone was mobilized a small distance proximally, and an enterotomy at the mid-sigmoid colon allowed its extraction. Serosal tears and an air leak were noted at the area of stone impaction distal to the enterotomy. Due to limited access and the necessity for local anaesthetic only, a loop colostomy was formed just proximal to the diseased bowel. The patient was discharged on postoperative day 5 and remains well in the community.

\section{Discussion}

A cholecystoenteric fistula, allowing gallstones to migrate into the bowel, was first described in 1654 [6]. Incidence was reported as 30-35 cases per million admissions in one large US hospital [7], and it is seen in $0.3-0.5 \%$ of all patients with gallstones [8]. It is the primary cause in less than $0.1 \%$ cases of mechanical bowel obstruction [1]. It is more commonly seen in female patients aged over 60 years (female to male ratio 9:1) $[9,10]$ and can present decades after cholecystectomy [11].

Cholecystitis with the pressure effect of a large gallstone is thought to cause gallbladder wall erosion and fistula formation, most commonly to the duodenum (32.5-96.5\%) but also to other parts of the gastrointestinal tract, such as the stomach (0-13.3\%), jejunum (0$2.5 \%)$, ileum (0-2.5\%) and colon (0-10.9\%; gallstone coleus) [5, 12]. Proximal migration or direct invasion to the stomach can result in the stone causing gastric outlet obstruction (Bouveret syndrome) [13] or being vomited [14]. The passage of gallstones large enough to cause obstruction is also reported following endoscopic retrograde cholangiopancreatography (ERCP) with sphincterotomy [15]. Once the gallstone has passed into the gastrointestinal tract, risk factors for impaction are hypothesized to be (1) if the stone is more than 2.5 $\mathrm{cm}$ [10], (2) if peristalsis carries the stone to a competent ileocaecal valve [5], and (3) if there is presence of co-existing disease such as malignancy, strictures, diverticulum, or sites of previous surgery or anastamoses [9, 16-19]. Migration of the gallstone to become impacted at the sigmoid colon, as described in this case, is nearly always associated with diverticular disease. Impaction at a sigmoid diverticular stricture can result in perforation of the previously diseased bowel [2]. Recurrent severe diverticulitis with stricturing is commonly described as a site of gallstone impaction [20]. Impaction in a patient with a history of previous pelvic irradiation and resultant sigmoid stricture has also been reported [21]. Other authors suggest narrowing from previous sigmoid polypectomy as causing the impaction and result- 


\section{Case Reports in Gastroenterology}

Case Rep Gastroenterol 2017;11:95-102

DOI: $10.1159 / 000456656$

c 2017 The Author(s). Published by S. Karger AG, Basel www.karger.com/crg

O'Brien et al.: Gallstone Ileus Caused by Cholecystocolonic Fistula and Impaction in the Sigmoid Colon: Novel Surgical Treatment with Trephine Loop Colostomy

ant perforation that mandated a sigmoid resection and end colostomy (Hartmann procedure) [22].

Clinical presentation includes abdominal pain and the spectrum of symptoms that are associated with bowel obstruction. Previous studies found an average of 1 week between onset of symptoms and hospitalization [23]. Abdominal CT has become the gold standard investigation with sensitivity of 93\% [24]. Rigler et al. [25] described 4 typical signs on plain abdominal film: obstruction, pneumobilia, an ectopic gallstone, and its migration on repeat imaging. Newer studies identify the CT signs of small bowel obstruction, an ectopic gallstone, and an abnormal gallbladder as suggestive for gallstone ileus [24]. Advantages of CT include identification of a contributing co-existent disease such as diverticular stricturing, and if contrast enhanced, it can determine bowel viability in cases where gallstone pressure necrosis has compromised the bowel viability, expediting surgical management. Histopathological examination will demonstrate ischaemic ulceration with perforation in these cases [26].

Definitive management to resolve the obstruction is usually required through surgery. Successful conservative management is described, in one case of gallstone impaction at the caecum following ERCP [15], but also after impaction in the sigmoid colon [27]. There has been debate between performing a simple enterolithotomy to deliver the impacted stone or combining this with definitive management of the gallbladder by cholecystectomy and fistula closure during the same procedure. The first operation, which leaves the cholecystoenteric fistula patent, unless the cystic duct is patent or the gallbladder has become fibrotic and shrunken due to repeated episodes of cholecystitis [17], results in recurrence rates of between 17 and 33\% $[8,5,28]$. Repeat episodes of biliary sepsis are not prevented. A study in the 1960s found a higher rate of gallbladder cancer in patients with cholecystoenteric fistula, but this has not been seen in newer studies $[9,29]$. Several modern case series describe equivalent or favourable mortality and morbidity rates when comparing simple enterolithotomy and removal of stone against definitive biliary surgery during the same procedure [30-33]. Of the larger published series, mortality for enterolithotomy alone is between 4.9 and $11.7 \%$, versus $7.25-16.9 \%$ for combination with cholecystectomy and closure of fistula $[1,34]$. This is supported by studies that describe increasing mortality with increasing invasiveness of surgery. Bowel resection during the procedure conferred $12.8 \%$ mortality in one study [34]. There is a role for delayed biliary surgery and fistula closure at a later date in a select group of patients for whom the prevention of recurrence or future biliary complications outweighs the risk [35], with mortality as high as $2.9 \%$ in this group [1]. Laparoscopically assisted approaches are described, which require mini-laparotomy to exteriorize the stone [36], but if preoperative CT can locate the point of impaction, the small incision needed for an enterolithotomy should suffice in most cases [24]. As this group of co-morbid patients often present late, have increased susceptibility to physiological disturbance, and can have severe predisposing disease that contributed to the gallstone impaction (such as complicated diverticular disease), minimally invasive surgery is strongly favoured, with the decision for more complicated surgery made on an individual basis [5, 31]. Sigmoid obstruction can rarely be resolved transanally, with sigmoid resection recommended especially in the presence of causative disease such as diverticular strictures [8]. Surgical options include the Hartmann procedure [2,37], primary closure of the enterolithotomy [3], or as in the described case, formation of a loop colostomy. Bowel wall compromise or perforation often mandates sigmoid resection, but if general anaesthetic is contraindicated and a short operating time needed, i.e., when the gallstone is removed and the obstructed bowel does not appear safe for suture repair but does not need formal resection, a defunctioning loop stoma can be created as the safest option. Previously, this has been described only under general 


\section{Case Reports in Gastroenterology}

Case Rep Gastroenterol 2017;11:95-102 DOI: $10.1159 / 000456656$

(c) 2017 The Author(s). Published by S. Karger AG, Basel www.karger.com/crg

O'Brien et al.: Gallstone Ileus Caused by Cholecystocolonic Fistula and Impaction in the Sigmoid Colon: Novel Surgical Treatment with Trephine Loop Colostomy

anaesthetic, and the gallstone was left in situ in the sigmoid colon [38]. This raises the risk of future migration or perforation, and the distention and pressure effect on the bowel wall has been thought to be a cause of pain in gallstone ileus [39]. One author describes milking the gallstone proximally to the caecum, whereby a modified appendicectomy allowed removal. Whilst preserving intestinal continuity, this approach mandates a much larger incision and risks damage to the large bowel when milking the stone and therefore may not be suitable for patients for whom regional or local anaesthesia is required [40].

Less common management options include oesophagogastroduodenoscopy to extract an obstructing stone from the stomach or duodenum [41]. Definitive removal of a colonic stone with colonoscopy was described in 1990 [42]. Endoscopic mechanical lithotripsy and laser lithotripsy have been described [43-45], but stone fragments can cause recurrence [46]. Balloon dilatation of diverticular strictures to facilitate endoscopic removal has also been reported [12, 47]. Reports describe combined balloon dilatation, with shockwave lithotripsy at the site of a previous ileo-colic anastomosis to treat impaction in the small bowel [4], and serial balloon dilatation with electrohydraulic lithotripsy for a sigmoid impaction [48].

\section{Conclusion}

There is clearly a role for combined endoscopic approaches for co-morbid patients in centres with the necessary endoscopic expertise. However, for most patients with gallstone ileus, especially if caused by a stone impacted in the sigmoid colon, the least invasive surgical option remains the mainstay of treatment. We have demonstrated that even when general anaesthetic is contraindicated due to co-morbidity, definitive relief of obstruction and removal of the impacted stone can be achieved through a very small incision, whilst accommodating for the diseased colon that is often found in such patients and which limits the choice of surgical intervention. Such an intervention is preferable to palliation of the patient and conservative management of bowel obstruction, which would ultimately result in bowel perforation and high mortality.

\section{Statement of Ethics}

The authors confirm that written informed consent was obtained from the patient for the publication of this case report and the accompanying images.

\section{Disclosure Statement}

The authors declare that there is no conflict of interest regarding the publication of this article.

\section{References}

Halabi WJ, Kang CY, Ketana N, et al: Surgery for gallstone ileus: a nationwide comparison of trends and outcomes. Ann Surg 2014;259:329-335. 
O'Brien et al:: Gallstone Ileus Caused by Cholecystocolonic Fistula and Impaction in the Sigmoid Colon: Novel Surgical Treatment with Trephine Loop Colostomy

- Mon-Martín F, Morales-Hernández A, Delgado-Plasencia L, et al: Gallstone ileus and intestinal perforation secondary to sigmoid diverticulum. Rev Esp Enferm Dig 2014;106:431-433.

-3 Osman N, Subar D, Loh M-Y, et al: Gallstone ileus of the sigmoid colon: an unusual cause of large-bowel obstruction. HPB Surg 2010;2010:153740.

4 Pezzoli A, Maimone A, Fusetti N, et al: Gallstone ileus treated with non-surgical conservative methods: a case report. J Med Case Rep 2015;9:15.

-5 Nuño-Guzmán CM, Marín-Contreras ME, Figueroa-Sánchez M, et al: Gallstone ileus, clinical presentation, diagnostic and treatment approach. World J Gastrointest Surg 2016;8:65-76. Martin F: Intestinal obstruction due to gall-stones: with report of three successful cases. Ann Surg 1912;55:725-743.

-7 Kurtz RJ, Heimann TM, Beck AR, et al: Patterns of treatment of gallstone ileus over a 45-year period. Am J Gastroenterol 1985;80:95-98.

8 Clavien PA, Richon J, Burgan S, et al: Gallstone ileus. Br J Surg 1990;77:737-742.

9 Abou-Saif A, Al-Kawas FH: Complications of gallstone disease: Mirizzi syndrome, cholecystocholedochal fistula, and gallstone ileus. Am J Gastroenterol 2002;97:249-254 Nakao A, Okamoto Y, Sunami M, et al: The oldest patient with gallstone ileus: report of a case and review of 176 cases in Japan. Kurume Med J 2008;55:29-33.

11 Zens T, Liebl RS: Gallstone ileus 30 years status postcholecystectomy. WMJ 2010;109:332-334.

12 Doddi S, Basu NN, Kamal T, et al: Large bowel obstruction due to gallstone: "gallstone coleus". Gd Rounds 2007;7:36-38.

13 Marco Doménech SF, López Mut JV, Fernández Garcia P, et al: Bouveret's syndrome: the clinical and radiological findings (in Spanish). Rev Esp Enferm Dig 1999;91:144-148. VanLandingham SB, Broders CW: Gallstone ileus. Surg Clin North Am 1982;62:241-247. Yamauchi Y, Wakui N, Asai Y, et al: Gallstone ileus following endoscopic stone extraction. Case Rep Gastrointest Med 2014;2014:271571. Fox PF: Planning the operation for cholecystoenteric fistula with gallstone ileus. Surg Clin North Am 1970;50:93-102. Frank A, Rogers RC: Gallstone intestinal obstruction. Calif Med 1958;88:140.

-18 Micheletto G, Danelli P, Morandi A, et al: Gallstone ileus after biliointestinal bypass: report of two cases. J Gastrointest Surg 2013;17:2162-2165.

-19 André Roncon Dias RIL: Biliary stone causing afferent loop syndrome and pancreatitis. World J Gastroenterol 2006;12:6229.

20 Sun R, Theilmann L, Vöhringer U, et al: Gallensteinileus bei Sigmastenose infolge rezidivierender Sigmadivertikulitis - eine seltene Komplikation des Gallensteinleidens. Med Klin 2010;105:433-436. Ishikura H, Sakata A, Kimura S, et al: Gallstone ileus of the colon. Surgery 2005;138:540-542. D’Hondt M, D’Haeninck A, Penninckx F: Gallstone ileus causing perforation of the sigmoid colon. J Gastrointest Surg 2011;15:701-702.

23 Coopermanj AM, Dickson ER, Remine WH: Changing concepts in the surgical treatment of gallstone ileus: a review of 15 cases with emphasis on diagnosis and treatmnent. Ann Surg 1968;167:377-383. Yu C-Y, Lin C-C, Shyu R-Y, et al: Value of CT in the diagnosis and management of gallstone ileus. World J Gastroenterol 2005;11:2142-2147. Rigler LG, Borman CN, Noble JF, et al: Gallstone obstruction. J Am Med Assoc 1941;117:1753. Ostrinsky Y, Bukeirat FA, Gayam S, et al: Gallstone ileus of the sigmoid colon mimicking colorectal malignancy. Gastrointest Endosc 2007;66:1028-1029. Anagnostopoulos GK, Sakorafas G, Kolettis T, et al: A case of gallstone ileus with an unusual impaction site and spontaneous evacuation. J Postgrad Med 2004;50:55-56. Kirkland KC, Croce EJ: Gallstone intestinal obstruction. A review of the literature and presentation of 12 cases, including 3 recurrences. JAMA 1961;176:494-497.

-29 Bossart PA, Patterson AH, Zintel HA: Carcinoma of the gallbladder. A report of seventy-six cases. Am J Surg 1962;103:366-369.

-30 Doko M, Zovak M, Kopljar M, et al: Comparison of surgical treatments of gallstone ileus: preliminary report. World J Surg 2003;27:400-404.

-31 Ravikumar R, Williams JG: The operative management of gallstone ileus. Ann R Coll Surg Engl 2010;92:279-281.

-32 Tan YM, Wong WK, Ooi LLPJ: A comparison of two surgical strategies for the emergency treatment of gallstone ileus. Singapore Med J 2004;45:69-72.

-33 Riaz N, Khan MR, Tayeb M: Gallstone ileus: retrospective review of a single centre's experience using two surgical procedures. Singapore Med J 2008;49:624-624. Reisner RM, Cohen JR: Gallstone ileus: a review of 1,001 reported cases. Am Surg 1994;60:441-446. Rodriguez-Sanjuan JC, Casado F, Fernandez MJ: Cholecystectomy and fistula closure versus enterolithotomy alone in gallstone ileus. Br J Surg 1997;84:634-637.

36 Moberg A-C, Montgomery A: Laparoscopically assisted or open enterolithotomy for gallstone ileus. Br J Surg 2007;94:53-57. 


\section{Case Reports in Gastroenterology}

\begin{tabular}{l|l}
\hline DOI: 10.1159/000456656 & $\begin{array}{l}\text { C } 2017 \text { The Author(s). Published by S. Karger AG, Basel } \\
\text { www.karger.com/crg }\end{array}$ \\
\hline
\end{tabular}

O'Brien et al.: Gallstone Ileus Caused by Cholecystocolonic Fistula and Impaction in the Sigmoid Colon: Novel Surgical Treatment with Trephine Loop Colostomy

-37 Qureshi NA, Dua S, Dua S, et al: Faecal peritonitis secondary to perforated recto sigmoid colon by a large gallstone: a case report. BMJ Case Rep 2009;2009:bcr10.2008.1105.

- 38 Carlsson T, Gandhi S: Gallstone ileus of the sigmoid colon: an extremely rare cause of large bowel obstruction detected by multiplanar CT. BMJ Case Rep 2015;2015:bcr2015209654.

-39 Masannat Y, Masannat Y, Shatnawei A: Gallstone ileus: a review. Mt Sinai J Med 2006;73:1132-1134.

40 Cargill A, Farkas N, Black J, et al: A novel surgical approach for treatment of sigmoid gallstone ileus. BMJ Case Rep 2015;2015:bcr2014209229.

41 Bedogni G, Contini S, Meinero M, et al: Pyloroduodenal obstruction due to a biliary stone (Bouveret's syndrome) managed by endoscopic extraction. Gastrointest Endosc 1985;31:36-38.

42 Roberts SR, Chang C, Chapman T, et al: Colonoscopic removal of a gallstone obstructing the sigmoid colon. J Tenn Med Assoc 1990;83:18-19.

43 Goldstein EB, Savel RH, Pachter HL, et al: Successful treatment of Bouveret syndrome using holmium: YAG laser lithotripsy. Am Surg 2005;71:882-885.

44 Huebner ES, DuBois S, Lee SD, et al: Successful endoscopic treatment of Bouveret's syndrome with intracorporeal electrohydraulic lithotripsy. Gastrointest Endosc 2007;66:183-184.

45 Balzarini M, Broglia L, Comi G, et al: Large bowel obstruction due to a big gallstone successfully treated with endoscopic mechanical lithotripsy. Case Rep Gastrointest Med 2015;2015:798746.

-46 Alsolaiman MM, Reitz C, Nawras AT, et al: Bouveret's syndrome complicated by distal gallstone ileus after laser lithotropsy using Holmium: YAG laser. BMC Gastroenterol 2002;2:15.

47 Garcia-López S, Sebastián JJ, Uribarrena R, et al: Successful endoscopic relief of large bowel obstruction in a case of a sigmoid colon gallstone ileus. J Clin Gastroenterol 1997;24:291-292.

-48 Zielinski MD, Ferreira LE, Baron TH: Successful endoscopic treatment of colonic gallstone ileus using electrohydraulic lithotripsy. World J Gastroenterol 2010;16:1533-1536.

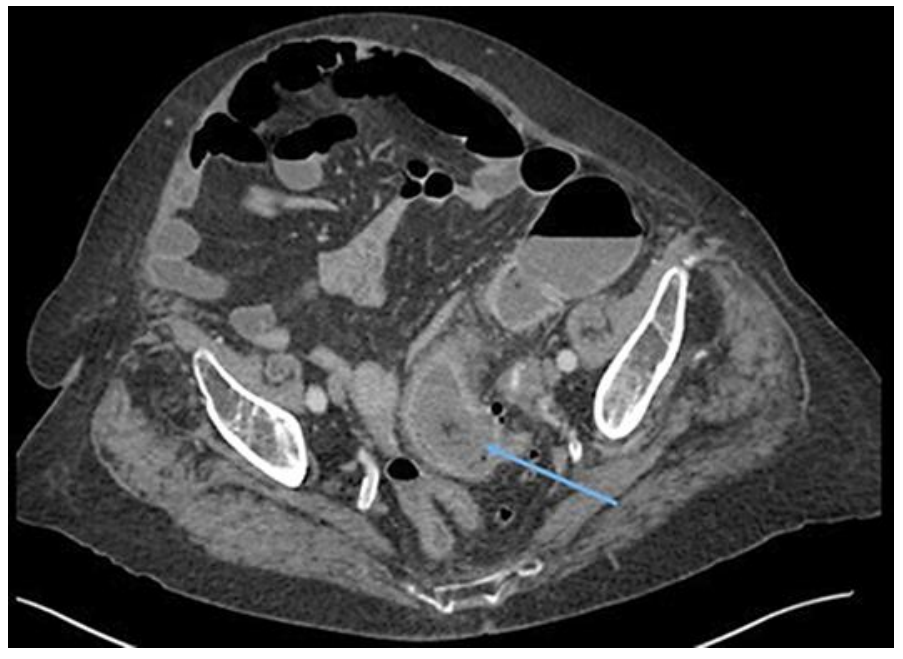

Fig. 1. CT abdomen axial slice showing cholecystocolonic fistula (arrow). 


\section{Case Reports in Gastroenterology}

\begin{tabular}{l|l}
\hline DOI: 10.1159/000456656 & C 2017 The Author(s). Published by S. Karger AG, Basel \\
\hline
\end{tabular} www.karger.com/crg

O'Brien et al: Gallstone Ileus Caused by Cholecystocolonic Fistula and Impaction in the Sigmoid Colon: Novel Surgical Treatment with Trephine Loop Colostomy

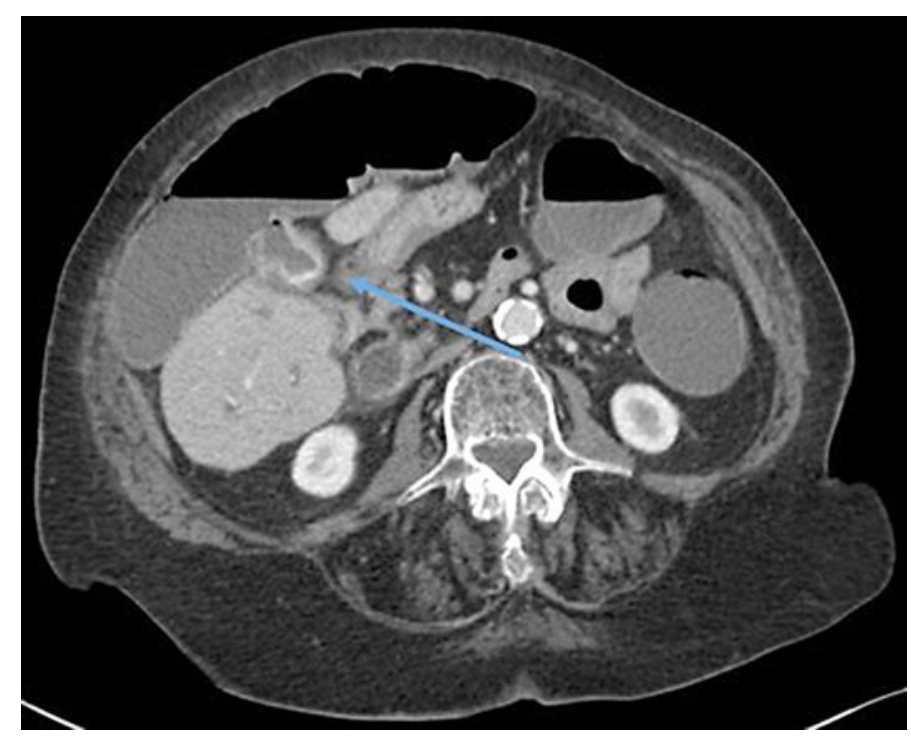

Fig. 2. CT abdomen axial slice showing obstructing gallstone in mid-sigmoid colon (arrow). 